\title{
Mapping Absolute Migration of the Indian Triple Junction Since 75 Ma and Implication for its Evolution
}

\author{
Desiderius C.P. Masalu* \\ University of Dar Es Salaam, Institute of Marine Sciences, P.O. Box 668, Zanzibar, Tanzania
}

\begin{abstract}
The absolute migration of the Indian Triple Junction (ITJ) or also known as the Rodriguez Triple Junction (RTJ) has been mapped using published data. The ITJ is made of the Southwest Indian Ridge (SWIR), the Central Indian Ridge (CIR) and the Southeast Indian Ridge (SEIR). The traces of the ITJ on the three plates (Africa, Antarctica, and Australia) were reconstructed to their former positions in the hotspot reference frame to map its absolute migration for the past 75 million years. The ITJ migrated northeasterly at a speed of $10 \mathrm{~cm} / \mathrm{yr}$ at $70 \mathrm{Ma}$ that declined gradually to $2.6 \mathrm{~cm} / \mathrm{yr}$ at $43 \mathrm{Ma}$ and thereafter remaining almost constant about $3.6-3.8 \mathrm{~cm} / \mathrm{yr}$, in a fairly straight trajectory suggesting a stable configuration of the ITJ since its formation. Because the most stable configuration known is the Ridge-Ridge-Ridge (RRR) triple junction, it is suggested that the configuration of the ITJ has been largely an RRR triple junction since its formation.
\end{abstract}

Keywords: Triple junction; absolute migration; palaeoposition; tectonics; magnetic lineations; mid-ocean ridges.

\section{INTRODUCTION}

Triple Junctions (TJ) are made of three physiographic features comprised of mid-ocean ridges and/or faults. The ITJ is defined by three ridges: the CIR which separates the African and Australia plates, the SWIR which separates the African and Antarctic plates, and the SEIR which separates the Australia (or Capricon) and Antarctic plates [1]. The ITJ forms one of the outstanding features on the Indian ocean seafloor. The ITJ is considered to have evolved since Chron 28 (64 Ma) when the Seychelles microplate drifted from India, giving birth to the Carlsberg Ridge [2-4]. The evolution of the ITJ since Chron 5 $(\sim 10 \mathrm{Ma})$ have been studied extensively $[2,5-8]$ and is relatively well constrained. For this period the most widely accepted model of evolution of the ITJ is alternating RRF (Ridge-Ridge-Fault) and RRR configurations. However, the evolution of the ITJ prior to $10 \mathrm{Ma}$ is only poorly understood due to the scarcity of geophysical data to allow such detailed studies to be done. Based on the apparently consistent configuration of the three ridges between 10 and $39 \mathrm{Ma}$ (Chron 18), it has been suggested that the configuration of the ITJ did not change during this period [9]. Similarly, available data for the period before Chron 18 is too sparse to accurately define the ITJ, but is sufficient to approximately define the trace of the ITJ location [4]. Based on paleogeographic reconstruction results of the central Indian ocean to derive past positions of the spreading axes at Chron 28 and 24, alternating RRF and RRR configurations [6] similar to the present configuration were proposed. Using updated data in the central Indian basin [9] reexamined the evolution of the ITJ between 65 and $49 \mathrm{Ma}$ (Chron 28 to 21). He suggested that between Chron 29 and 24 the ITJ followed either an unstable RRR or more likely, a pseudo RRF mode: and that between Chron 24 and 21 the evolution was characterized by a predominant RFF

*Address correspondence to this author at the University of Dar Es Salaam, Institute of Marine Sciences, P.O. Box 668, Zanzibar, Tanzania; Tel: +255 24 2230741; Fax: +255 24 2233050; E-mail: masalu@ims.udsm.ac.tz configuration that episodically turned to a transient RRR configuration. Based on the various studies, since the formation of the ITJ in Late Cretaceous the three plates meeting at the junction were successively (i) the African, Antarctica and Indian plates until Chron 20 ( $44 \mathrm{Ma}$ ) when the Wharton ridge between India and Australia became inactive [10]; (ii) the African, Antarctica and Indo-Australian plates from Chron 20 to the formation of a diffuse boundary zone between the Indian and Australian plates when compression was initiated in the central Indian Ocean about $10 \mathrm{Myr}$ ago $[11,12]$ and (iii) the African, Antarctica and Australian plates since $10 \mathrm{Ma}$ [1].

In this study, the migration of the ITJ in the hotspot reference frame since $75 \mathrm{Ma}$ to Present was mapped. The ITJ has been migrating northeasterly along a fairly straight-line trajectory which suggests a stable configuration, in favor of the RRR configuration since its formation.

\section{METHODS OF ANALYSIS AND DATA}

Magnetic anomaly lineations form concurrently with new seafloor on mid-ocean ridges. On the other hand, a trace of a triple junction is a trajectory that records past locations of the triple junction. Therefore, if there exists points of intersection between a trace of a $\mathrm{TJ}$ and identified magnetic lineations, and a relevant model of absolute motion of the plate on which the trace of the TJ resides, absolute paleopositions of the TJ can be reconstructed by backtracking the points of intersections to their former positions $[13,14]$. However, this method should be used cautiously in cases where the intersections of magnetic lineations with same age on the two sides of the trace of the TJ are significantly dislocated. Significant dislocations of same age isochrones along the TJ trace can be caused by the existence of an RRF triple junction. In such situations, consistence dislocations should be observed on two adjacent traces of the TJ, and care needs to be taken to choose the correct intersections that were created at the triple junction for use in the reconstructions. This scenario is represented in Fig. (1) in which dislocations exist along the TJT-A and TJC-C due 
to the existence of a RRF triple junction. For the trace on plate A, i.e., TJT-A same-age intersections that are relatively far away from the $\mathrm{TJ}$ should be used while on the trace on plate $\mathrm{C}$, i.e., TJT-C same-age intersections that are relatively closer to the TJ should be used. From the derived successful paleolocations of intersections of magnetic lineations with the TJ traces, which represents the migration trajectory of the triple junction, absolute migration speeds of the ITJ were computed.

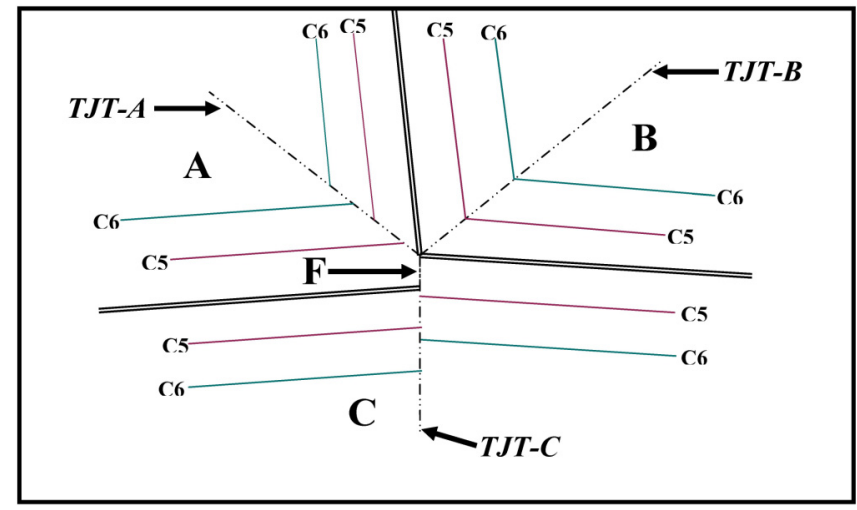

Fig. (1). Schematic map of an RRF triple junction. A, B and $\mathbf{C}$ are tectonic plates separated by spreading centres indicated in double lines and a fault F. C5 and C6 are chron age of magnetic lineations. TJT-A $=$ trace of the triple junction on the plate $\mathbf{A} ; \mathbf{T J T}-\mathbf{B}=$ trace of the triple junction on the plate $\mathbf{B}$; TJT-C $=$ trace of the triple junction on the plate $\mathbf{C}$.

In this study published data, that is, figure 1 of [4] was used as the base map from which the intersection points of magnetic lineations and the TJ traces, for all three traces of the ITJ were digitized using a Calcomp digitizer. The detailed information about these data i.e., the surveys and research works, their extents, parameters measured, etc are provided in [4]. The paleopositions of the ITJ were successively reconstructed using [15] models of absolute plate motions for the (i) African and Antarctica plates since the formation of the ITJ in Late Cretaceous to Present for the TJTs on respective plate and (ii) the Indian plate until Chron 20, the Indo-Australian plate from Chron 20 to Chron 5, and the Australian plate form Chron 5 to Present for the TJT on the Australian plate. These models are based on the Indo-Atlantic hotspots reference frame. Chron ages were assigned based on the geomagnetic polarity time scale for Late Cretaceous and Cenozoic time [16]. Details on how TJ traces can be identified and mapped have been published elsewhere [e.g., 4, 8].

The trace of the ITJ on the Australian plate marks the intersection of the CIR and SEIR at the TJ. The two ridges have quite similar spreading rates [9] and the intersections of magnetic lineations of the same age with the TJ trace are very consistent. Thus there was no problem for deciding which set of intersection points to digitize, for use in reconstructing the paleolocations of ITJ.

For the trace of the ITJ on the African and Antarctic plates things are not straightforward. There is one major difficulty, which is the scarcity and complexity of identified magnetic lineations formed by the CIR on the African plate $[5,17,18]$, and those formed by the SWIR on both, the African and Antarctic plates. This prevents the intersection points between the TJ traces and magnetic lineations that were formed by the SWIR from being accurately determined. Furthermore, based on tectonic setting of the Indian Ocean basin (Fig. 2) the SWIR appears to be propagating into crust that was formed by the CIR and the SEIR [14]. Previous work have suggested that processes involved on the SWIR close to the TJ are more likely related to extension of the SEIR and the CIR crusts than normal spreading at the SWIR axis [19, 20]. Because the SWIR appears to be propagating into the crust that was formed by the CIR and the SEIR, results obtained by reconstructing intersection points between the $\mathrm{TJ}$ traces and magnetic lineations that were formed by the CIR and the SEIR on the African and the Antarctic plates respectively, will constrain the migration trajectory of the ITJ based on magnetic lineations formed by the SWIR, as this should lie between the two reconstructed trajectories.

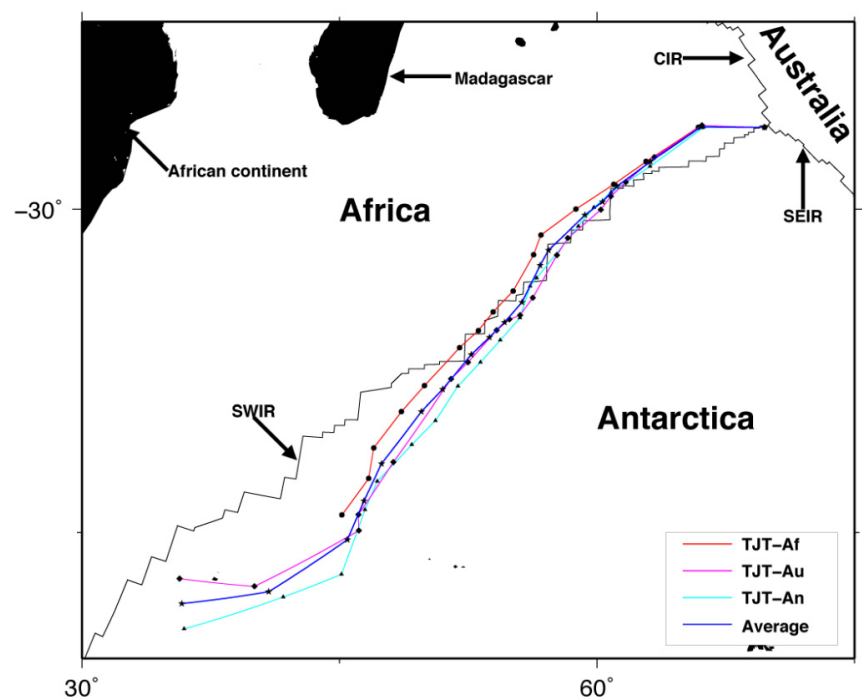

Fig. (2). Reconstructed absolute paleolocations of the ITJ traces. Red line with solid circles is reconstruction based on TJT-Af; Purple line with diamonds is reconstruction based on TJT-Au; Green line with triangles is reconstruction based on TJT-An; Blue line with stars is the average reconstructions based on the three traces. Diamonds, triangles, solid circles and stars represent Chron ages $0,5,6,8,11,13$, $18,20,21,22,23,24,25,26,27,28,29,31$, and 32 sequentially from the TJ. Note that TJT-Af does not have Chron 11, 31, and 32. Other panels as in Fig. (1).

\section{RESULTS AND DISCUSSION}

Fig. (2) shows the results obtained from reconstructions in this work. Reconstructions based on the three TJ traces: on the Indo-Australian, African, and Antarctic plates, yield coincident migration trajectories for the ITJ. The ITJ appears to have been migrating northeasterly since $64 \mathrm{Ma}$ (Chron 28). The migration trajectories do not indicate any major changes in migration direction that could be related to instability or major changes in the configuration of the ITJ. The fairly straight-line trajectory suggests that the configuration of the ITJ has been mostly stable throughout since $65 \mathrm{Ma}$, in favor of the RRR (RidgeRidge-Ridge) configuration. Detailed studies of the evolution of the ITJ indicated that some cyclic processes play a key role in maintaining a stable ITJ. Other researchers [21] studied sidescan data from GLORIA [22] of the ITJ traces on the Antarctic and African plates for the past $20 \mathrm{Ma}$. The data indicated two cyclic modes of evolution in which one was represented by continuous linear traces which was attributed to the stable RRR mode, and the other by a series of en echelon scraps indicating 
a none-RRR mode. To explain this [21] proposed a cyclic evolution model of the ITJ that involved the segmentation and temporary detachment of the CIR from the junction. . It is proposed here that this process have played a key role in continually returning the ITJ in the stable RRR mode from the unstable RRF mode (e.g., [23]) in the past $65 \mathrm{My}$. Additionally, the reconstructed position of the ITJ (Fig. 2) nearly coincides with the present-day position of the SWIR since Chron $24(\sim 53$ Ma), except for Chron 5. This might imply that the ridge significantly migrated towards the south in the hotspot reference frame since Chron 5.

Fig. (3) shows absolute migration speed of the ITJ. The average speed decreased since about $65 \mathrm{Ma}$ from $10 \mathrm{~cm} / \mathrm{yr}$ to about $2.6 \mathrm{~cm} / \mathrm{yr}$ at $43 \mathrm{Ma}$. From $41 \mathrm{Ma}$ to Present the migration speed have remained almost constant between $3.6-3.8 \mathrm{~cm} / \mathrm{yr}$. The timing of the change of absolute migration speed of the ITJ at $41 \mathrm{Ma}$ coincides with several reorganizations that occurred in the Indian Ocean around Chron 18 to Chron 20 (40 - 44 Ma) nearly coeval with the beginning of the India-Eurasia collision: (i) the time when the Wharton ridge in the Central Indian Basin became inactive [10]; (ii) the change of the spreading direction along the Southeast Indian Ridge from north-south (N-S) to $\sim \mathrm{N} 30^{\circ} \mathrm{E}$ and the spreading rate decreased from $140 \mathrm{~mm} / \mathrm{yr}$ to $60 \mathrm{~mm} / \mathrm{yr}$ [4]; and (iii) Australia began to separate from Antarctica [24]. The slowing of the ITJ at $41 \mathrm{Ma}$ when considered at a regional scale could be interpreted to be due to the India-Eurasia collision (e.g., [4]). However, at a global scale the timing of the change in migration speed of the ITJ is
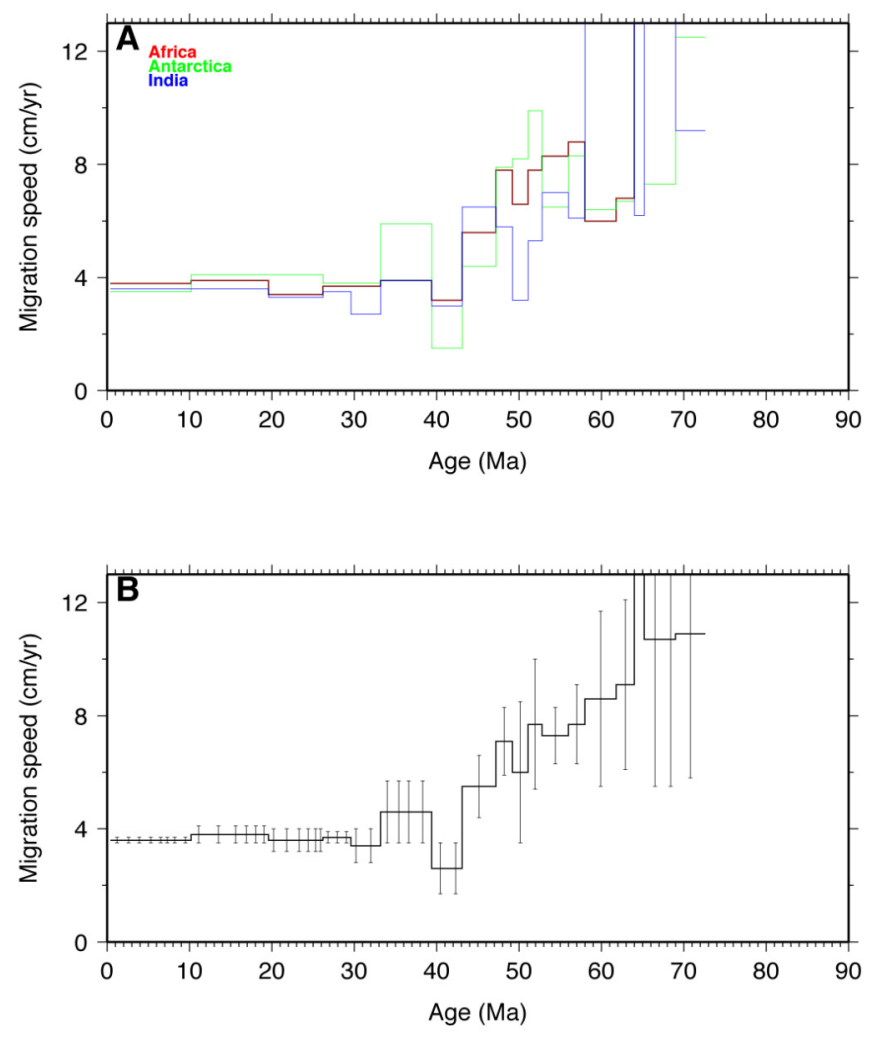

Fig. (3). Absolute migration speed of the ITJ since 90 Ma to present. (A) Green solid line based on the TJT-An, red solid line based on the TJT-Af, purple solid line based on TJT-Au. (B) Stacked profile of absolute migration speed of the ITJ (based on A profiles) with errors shown as deviations from the mean. coincident with the Emperor-Hawaii bend in the Pacific Ocean (e.g., [25]). Several recent studies have shown that the Hawaii hotspot rapidly migrated southward (at over $4 \mathrm{~cm} /$ year) prior to the Hawaii-Emperor bend time [26-28] and suggested that the slowing of hotspot motion was the dominant factor in forming the Emperor-Hawaii bend. Other investigators [29] attributed the southerly motion of the Hawaii hotspot to the mantle flow. The Hawaii-Emperor bend have been correlated to several observable contemporaneous features/events in the Circum Pacific region (e.g., [30]). Because the absolute plate motion model of [15] used in this study was mainly derived based on the Indian ocean hotspots, we suggest that the slowing of the ITJ at the Emperor-Hawaii timing together with the several coincident reorganizations in the Indian Ocean may be related to a global event probably change in mantle flow or plate reorganization (e.g., [31]). Some investigators [18] have noted that it was difficult to imagine that contemporaneous events in the Pacific and Indian oceans could occur independently of each other. They suggested that a plate tectonic event may occur along a particular path and could be transmitted along some global plate tectonic boundaries.

\section{CONCLUSIONS}

The absolute migration of the ITJ in the Indian Ocean for the past $75 \mathrm{Ma}$ has been reconstructed using the intersection points of magnetic lineations and the triple junction traces. The ITJ traces on the African, Australia, and Antarctic plates show coincident trajectories defining a consistent trace for the ITJ. Furthermore, the migration trajectories do not indicate any major changes in direction suggesting that the ITJ has had a stable configuration since $65 \mathrm{Ma}$. On this basis, the RRR configuration for the ITJ is suggested. The estimated ITJ trajectory indicates that since 65 Ma the ITJ has been migrating northeasterly. The migration speed of the ITJ decreased from $10 \mathrm{~cm} / \mathrm{yr}$ at $70 \mathrm{Ma}$ to about $2.6 \mathrm{~cm} / \mathrm{yr}$ at $43 \mathrm{Ma}$, and thereafter (at about $41 \mathrm{Ma}$ ) has remained almost constant at 3.6-3.8 cm/yr to Present. The coincidence of the timing at $41 \mathrm{Ma}$ with other major event such as the Emperor-Hawaii bend and the 'death' of the Wharton ridge may suggest a major global plate or mantle reorganization.

\section{ACKNOWLEDGEMENTS}

I would like to express my sincere acknowledgement to JSPS of Japan for offering me a postdoctoral fellowship during which I was able to make this paper. I thank much the referees, Dr M Fournier and an anonymous reviewer, for their critical yet constructive comments that helped to improve much the quality of this paper. I would also like to acknowledge the friendly cooperation I got from Prof. Dr K Tamaki of the Ocean Research Institute, University of Tokyo (now at the Department of Geosystem Engineering, University of Tokyo), who was my host researcher. Members of the Ocean-floor Geotectonics Division at ORI provided a conducive research environment.

\section{REFERENCES}

[1] J.Y. Royer and R.G. Gordon, "The motion and boundary between the Capricorn and Australian plates", Science, vol. 277, no. 5330, pp. 1268-1274, 1997.

[2] D.P. McKenzie and J.G. Sclater, "The evolution of the Indian ocean since the Late Cretaceous", Geophys. J. R. Astro. Soc., vol. 25, pp. 437-528, 1971. 
[3] P. Patriat, "Reconstitution de l'Évolution du Systéme de Dorsales de l'Océan Indien par les Méthodes de la Cinématique des Plaques", Territoire des Terres Australes et Antarctiques Françaises, Paris, 1987, p. 308.

[4] P. Patriat and J. Segoufin, "Reconstruction of the Central Indian Ocean", Tectonophysics, vol. 155, pp. 211-234, 1988.

[5] C.R. Tapscott, P. Patriat, R.L. Fisher, J.G. Sclater, H. Hoskins and B. Parsons, "The Indian Ocean Triple Junction", J. Geophys. Res., vol. 85, pp. 4723-4739, 1980.

[6] P. Patriat and V. Courtillot, "On the stability of triple junctions and its relation to episodicity in spreading", Tectonics, vol. 3, pp. 317-332, 1984.

[7] M. Munschy and R. Schlich, "The Rodriguez Triple Junction (Indian Ocean): structure and evolution for the past one million years", Mar. Geophys. Res., vol. 11, pp. 1-14, 1989.

[8] D. Sauter, V. Mendel, C. Rommevaux-Jestin, P. Patriat, and M. Munschy, "Propagation of the Southwest Indian Ridge at the Rodrigues Triple Junction”, Mar. Geophys. Res., vol. 19, pp. 553-567, 1997.

[9] J. Dyment, "Evolution of the Indian Triple Junction between 65 and $49 \mathrm{Ma}$ (Anomalies 28 to 21)", J. Geophys. Res., vol. 98, pp. 1386313877, 1993.

[10] C.S. Liu, J.R. Curray and J.M. McDonald, "New constraints on the tectonic evolution of the eastern Indian Ocean", Earth Planet Sci. Lett., vol. 65, pp. 331-342, 1983.

[11] J.R. Cochran, "Himalayan uplift, sea level and the record of Bengal Fan sedimentation at the ODP LEG 116 Sites", Proc. ODP, Sci. Results, vol. 116, pp. 397-414, 1990.

[12] M. Delescluse and N. Chamot-Rooke, "Instantaneous deformation and kinematics of the India-Australia plate", Geophys. J. Int., vol. 168, pp. 818-842, 2007.

[13] D.C.P. Masalu and K. Tamaki, "Highlights on global absolute motion and tectonics of the mid-ocean ridge system from 85 Ma to present", Japan Earth and Planetary Science Joint Meeting, abstr. 1994, p. 159.

[14] D.C.P. Masalu, "Mapping absolute migration of global mid-ocean ridges since 80 Ma to Present", Earth Planet Space, vol. 59, pp. 10611066, 2007.

[15] R.D. Müller, J.Y. Royer and L.A. Lawver, "Revised plate motions relative to the hotspot from combined Atlantic and Indian Ocean hotspot tracks", Geology, vol. 21, pp. 275-278, 1993.

[16] S.C. Cande and D.V. Kent, "Revised calibration of the geomagnetic polarity timescale for the late Cretaceous and Cenozoic", J. Geophys. Res., vol. 100, pp. 6093-6095, 1995.

[17] J.G. Sclater, R.L. Fisher, P. Patriat, C.R. Tapscott, and B. Parsons, "Eocene to recent development of the South-west Indian Ridge, a consequence of the evolution of the Indian Ocean Triple Junction", Geophys. J. R. Astro. Soc., vol. 64, pp. 587-604, 1981.
[18] P. Patriat, H. Sloan and D. Sauter, "From slow to ultraslow: A previously undetected event at the Southwest Indian Ridge at ca 24 Ma”, Geology, vol. 36, pp. 207-210, 2008.

[19] P. Patriat and L. Parson, "A survey of the Indian ocean triple junction trace within the Antarctic plate: implications for the junction evolution since 15 Ma", Mar. Geophys. Res., vol. 11, pp. 89-100, 1989.

[20] N.C. Mitchell, "Distributed extension at the Indian ocean triple junction”, J. Geophys. Res., vol. 96, pp. 8019-8043, 1991.

[21] C. Honsho, K. Tamaki and H. Fujimoto, "Three-dimensional magnetic studies of the Rodriguez Triple Junction in the Indian Ocean”, J. Geophys. Res., vol. 101, pp. 15837-15848, 1996.

[22] N.C. Mitchell and L.M. Parson, "The tectonic evolution of the Indian Ocean triple junction, anomaly 6 to present", J. Geophys. Res., vol. 98, pp. 1793-1812, 1993.

[23] M. Fournier, C. Petit, C. Chamot-Rooke, O. Fabbri, P. Huchon, B. Maillot, and C. Lepvrier, "Do ridge-ridge-fault triple junctions exist on Earth? Evidence from Aden-Owen-Carlsberg junction in the NW Indian Ocean", Basin Res., vol. 20, no. 4, 2008.

[24] B.J. Brown, R.D. Muller, C. Gaina, H.I.M. Struckmeyer, H.M.J. Stagg and P.A. Symonds, "Formation and evolution of Australian passive margins: Implications for locating the boundary between continental and oceanic crust", Geol. Soc. Am. Spec. Pap., vol. 372, pp. 223-243, 2003.

[25] D.C. Engebretson, A. Cox and R.G. Gordon, "Relative motions between oceanic and continental plates in the Pacific basin", Geol. Soc. Am. Special paper, 1985.

[26] J.A. Tarduno, R.A. Duncan, D.W. Scholl, R.D. Cottrell, B. Steinberger, T. Thordarson, B.C. Kerr, C.R. Neal, F.A. Frey, M. Torii and C. Carvallo, "The emperor seamounts: southward motion of the hawaiian hotspot plume in earth's mantle", Science, vol. 301, pp. 1064-1069, 2003.

[27] R.A. Duncan and R.A. Keller, "Radiometric ages for basement rocks from the Emperor Seamounts", ODP Leg 197, Geochem. Geophys. Geosyst., vol. 5, Q08L03, 2004.

[28] J.A. Tarduno, "On the motion of Hawaii and other mantle plumes", Chem. Geol., vol. 241, pp. 234-247, 2007.

[29] B. Steinberger, R. Sutherland, and R.J. O'Connell, "Prediction of Emperor-Hawaii seamount locations from a revised model of global plate motion and mantle flow", Nature, vol. 430, pp. 167-173, 2004.

[30] P. Wessel, Y. Harada and L.W. Kroenke, "Towards a self-consistent, high-resolution absolute plate motion model for the Pacific", Geochem. Geophys. Geosyst., vol. 7, Q03L12, 2006.

[31] J.M. Whittaker, R.D. Muller, G. Leitchenkov, H. Stagg, M. Sdrolias, C. Gaina, and A. Goncharov, "Major Australian-Antarctic plate reorganization at hawaiian-emperor bend time", Science, vol.318, pp. 83-86, 2007.

(C) Desiderius C.P. Masalu; Licensee Bentham Open.

This is an open access article licensed under the terms of the Creative Commons Attribution Non-Commercial License (http://creativecommons.org/licenses/by-nc/3.0/) which permits unrestricted, non-commercial use, distribution and reproduction in any medium, provided the work is properly cited. 